\title{
Internacionalização e seus reflexos na gestão da qualidade da pós-graduação em Educação
}

\section{Internationalization and its effects on postgraduate quality management in Education}

\author{
Internacionalización y sus efectos en la gestión de \\ calidad de posgrado en Educación
}

\author{
Eliane Souza de Carvalho ${ }^{1}$ \\ Giselle Cristina Martins Real²
}

DOI: http://dx.doi.org/10.20435/serie-estudos.v25i54.1389

\begin{abstract}
Resumo: Este texto tem como objetivo analisar os indicativos de internacionalização consubstanciados na avaliação da pós-graduação em Educação. Trata-se de uma pesquisa documental, que tem como base de análise os Documentos de Área da Educação 2009, 2013, 2016 e 2019, bem como os respectivos Relatórios das Avaliações 2010, 2013 e 2017. A pesquisa evidenciou que a política nacional de educação superior está alinhada a uma agenda globalmente estruturada para educação (DALE, 2004), fazendo com que o processo de internacionalização deixe de ser uma opção e passe a ser obrigatoriedade para as universidades. A internacionalização tem ocupado um crescente espaço na política de avaliação da pós-graduação. Para além da produção intelectual, o que tem balizado a qualidade na pós-graduação são as ações de internacionalização, pois esta, além de ser elemento que distingue os programas 6 e 7, passou a compor a ficha avaliativa para o quadriênio 2017-2020, tornando-se um indicador de qualidade a ser considerado por todos os programas.
\end{abstract}

Palavras-chave: internacionalização; avaliação; pós-graduação.

\begin{abstract}
This text aims to analyze the indications of internationalization embodied in the evaluation of postgraduate education. It is a documentary research based on the Education Area Documents 2009, 2013, 2016, and 2019, as well as the respective Assessment Reports 2010, 2013, and 2017. The research showed that the national policy of higher education is aligned with a globally structured agenda for education (DALE, 2004), making the internationalization process no longer an option and becomes mandatory for universities. Internationalization has occupied a growing space in the policy of postgraduate evaluation. Beyond that intellectual production, what has been the hallmark of postgraduate quality are the internationalization actions, whereas, besides being an element that distinguishes the programs 6 and 7, it is now part of the evaluation sheet for the 2017-2020 quadrennial, becoming a quality indicator to be considered by all programs.
\end{abstract}

Keywords: internationalization; evaluation; postgraduate studies.

1 Universidade Estadual de Mato Grosso do Sul (UEMS), Dourados, Mato Grosso do Sul, Brasil.

2 Universidade Federal da Grande Dourados (UFGD), Dourados, Mato Grosso do Sul, Brasil. 
Resumen: Este artículo tiene como objetivo analizar las indicaciones de internacionalización incorporadas en la evaluación de la educación de posgrado. Ésta es una investigación documental basada en los Documentos del Área de Educación 2009, 2013, 2016 y 2019, así como en los respectivos Informes de Evaluación 2010, 2013 y 2017. La investigación mostró que la política nacional de educación superior está alineada con una agenda de educación estructurada globalmente (DALE, 2004), lo que hace que el proceso de internacionalización ya no sea una opción, sino una necesidad para las universidades. La internacionalización ha ocupado un espacio creciente en la política de evaluación de posgrado. Más allá de la producción intelectual, lo que ha sido el sello distintivo de la calidad de posgrado son las acciones de internacionalización, ya que esa, además de ser un elemento que distingue los programas 6 y 7 , ahora forma parte de la hoja de evaluación para el cuadrienio 2017-2020, convirtiéndose en un indicador de calidad para ser considerado por todos los programas.

Palabras clave: internacionalización; evaluación; posgrado.

\section{INTRODUÇÃO}

A construção da política de avaliação da educação superior tem buscado imprimir um consenso de qualidade em torno das ações de internacionalização. Os documentos orientadores dessa política postulam uma proposta hegemônica trabalhada no nível do consenso pelos agentes governamentais, por meio de agências de avaliação e fomento como a Coordenação de Aperfeiçoamento de Pessoal de Nível Superior (Capes) e o Conselho Nacional de Desenvolvimento Científico e Tecnológico (CNPQ). Isso seria uma estratégia para assegurar a hegemonia do modelo de internacionalização proposto de outro modo que não apenas a coerção (GRAMSCI, 2016).

A busca pela excelência acadêmica insere-se em um movimento amplo de diferenciação, expansão e internacionalização da educação superior, caracterizado pela convergência no âmbito das redes de políticas globais, indicando que a produção do consenso assume relevância como forma de manutenção da hegemonia (THIENGO, 2018). Com a crescente globalização e internacionalização dos processos educativos, a avaliação assume um papel de protagonismo na agenda da internacionalização da educação superior (ROBL, 2015).

Assim, este texto tem como objetivo analisar os indicativos de internacionalização consubstanciados na avaliação da pós-graduação em Educação. Trata-se de uma pesquisa documental que terá como base de análise os Documentos de Área 2009, 2013, 2016 e 2019 e Relatórios das Avaliações 2010, 2013 e 2017. 
Trabalha-se com análise documental por considerar o documento escrito uma fonte de informações estáveis, que serve para fundamentar os pressupostos da pesquisa. Segundo Cellard (2008, p. 295), tem-se nos documentos uma fonte preciosa e insubstituível, que na maioria das vezes representa a quase totalidade das atividades de determinada época e sintetiza as concepções que permearam as atividades desenvolvidas ou a se desenvolver.

Para atender ao objetivo do texto, este artigo foi dividido em três seções, além das considerações finais. A primeira seção trata da construção do conceito de internacionalização, a segunda seção explicita a relação entre os processos de internacionalização e globalização, e a terceira analisa a indução da internacionalização como conceito de qualidade na área de Educação.

\section{A CONSTRUÇÃO DO CONCEITO DE INTERNACIONALIZAÇÃO}

Morosini (2006, p. 115) adverte que a "internacionalização da educação é um conceito complexo, com uma diversidade de termos relacionados, apresentando diversas fases de desenvolvimento". Ainda assim, neste texto, tem-se como referência o conceito apresentado por Knight:

A internacionalização é um processo que leva à integração da dimensão internacional, intercultural e global às metas, funções e implementação do ensino superior. Assim sendo, trata-se de um processo de mudança - adaptado para atender necessidades e interesses individuais de cada instituição. Consequentemente, não existe um modelo "genérico" para a internacionalização. [...] A internacionalização enfatiza o relacionamento entre as nações, povos, culturas, instituições e sistemas. (KNIGHT, 2012, p. 1).

Esses processos de internacionalização podem ser analisados a partir de três dimensões: a) global/regional - com foco nas discussões que marcaram os anos 1990 com uma reordenação econômica, com forte presença da globalização em diferentes níveis, inclusive educacional; b) nacional - reflete as discussões quanto à presença do Estado avaliador, constitui-se por meio de políticas, financiamentos, programas e marcos regulatórios; $c$ ) institucional - em que ocorre o processo real de internacionalização (MOROSINI; NASCIMENTO, 2017).

Na dimensão nacional, são abordadas questões relacionadas ao Estado enquanto agente indutor na construção dessa política, buscando relacionar que a internacionalização na pós-graduação é fruto de interesses e condições 
preestabelecidas que têm se materializado nas notas atribuídas aos programas considerados de excelência.

Na dimensão institucional, são desenvolvidas políticas que tratam de aspectos específicos da internacionalização e/ou que integram e apoiam a dimensão na missão primária e nas funções da instituição, refletindo a implementação das políticas e dos programas de educação superior nas universidades (KNIGHT, 2012, p. 17). Acredita-se que essas ações são verificáveis na produção acadêmica científica; nos programas de cooperação internacional e intercâmbio de docentes e discentes; e nos projetos desenvolvidos nas ações do grupo gestor dos programas.

A globalização acelerou e criou novos panoramas para a internacionalização da educação superior, mas o conceito de internacionalização não é algo novo, ele vem evoluindo ao longo do tempo. Em 1993, Knight, uma das pesquisadoras da temática que é referenciada internacionalmente, definiu internacionalização como o processo de integração da dimensão internacional entre ensino, pesquisa e funções e serviços das instituições de educação superior. A internacionalização era definida no nível institucional, sendo relacionada às múltiplas atividades, programas, serviços, intercâmbios internacionais e cooperação técnica. Em 1994, a mesma autora propôs uma nova definição, passando a considerar que:

Internacionalização da educação superior é um processo de integração da dimensão internacional no ensino/aprendizagem, pesquisa e funções de serviço de uma universidade ou faculdade. Uma dimensão internacional significa uma perspectiva internacional/intercultural/global nas principais funções de uma instituição de educação superior". (KNIGHT, 1994, p. 3, tradução livre).

Nesta definição, tem-se a introdução de uma abordagem organizacional, mostrando que a internacionalização era um processo que precisava estar integrado e ser sustentado no nível institucional. Knight (2003) justifica que, dadas as mudanças ocorridas nas justificativas, nos fornecedores e nos métodos do ensino superior transfronteiriço e a necessidade de a internacionalização ser entendida tanto no nível nacional, setorial, quanto institucional, fez-se importante reexaminar a definição, de forma a garantir que o significado reflita essas mudanças.

Assim, foi proposta uma nova definição para o termo internacionalização: "A internacionalização nos níveis nacional, setorial e institucional é definida como 
o processo de integração de uma dimensão internacional, intercultural ou global ao propósito, funções ou prestação de educação pós-secundária" (KNIGHT, 2003, p. 2, tradução livre).

Os termos e conceitos utilizados nessa definição foram cuidadosamente escolhidos (KNIGHT, 2003; 2004). A autora explica que processo é usado para transmitir a ideia de um esforço contínuo, denotando uma qualidade evolutiva; dimensões internacionais, interculturais e globais são utilizadas para indicar a amplitude do termo; internacional é utilizado no sentido de relações entre as nações, culturas ou países; intercultural, para abordar os aspectos da internacionalização em casa; global é incluído para fornecer o sentido de abrangência mundial; integração é utilizado no sentido de incorporar a divisão internacional e intercultural em programas e políticas; propósito, função e prestação são conceitos que devem estar juntos, pois referem-se ao papel e aos objetivos gerais que a Educação tem para o país/região ou uma instituição, usando esses três termos a definição pode ser relevante para o nível setorial, para o nível institucional e para a variedade de provedores do campo educacional.

Em trabalho produzido em 2013, Knight mantém essa conceituação justificando que uma definição não deve padronizar ou homogeneizar o processo de internacionalização em todo o mundo, é necessário, sim, "que a dimensão internacional esteja relacionada a todos os aspectos da educação superior e ao papel que ela desempenha na sociedade" (KNIGHT, 2013, p. 85, tradução livre).

De Witt et al. (2015), em estudo solicitado pela Comissão de Cultura e Educação do Parlamento Europeu sobre a internacionalização da educação superior, apontam ter realizado uma revisão na definição de internacionalização comumente aceita de Knight, passando a trabalhar coma seguinte definição:

Internacionalização da educação superior é um processo intencional de integrar uma dimensão internacional, intercultural ou global no propósito, funções e entrega da educação pós-secundária, a fim de melhorar a qualidade da educação e pesquisa para todos os alunos e funcionários e para fazer uma contribuição significativa para a sociedade. (DE WITT et al., 2015, p. 29, tradução livre).

Essa revisão conceitual procurou destacar três pontos-chave (EUROPEAN ASSOCIATION FOR INTERNATIONAL EDUCATION [EAIE], 2015): indicação de que o processo é planejado e intencional - um processo intencional é de consideração, 
decisão e ação; conscientização de que o processo precisa ser mais inclusivo e menos elitista, ser parte integrante de um currículo internacionalizado para todos os alunos; inclusão do aspecto pessoal, uma vez que há uma dependência do engajamento ativo e comprometido de todos os membros das instituições de educação superior, por meio de funções acadêmicas e de gestão.

\section{OS PROCESSOS DE INTERNACIONALIZAÇÃO NO CONTEXTO DA GLOBALIZAÇÃO}

A partir das reformas dos anos 1990, as instituições de nível superior foram colocadas na rota de uma sociedade globalizada, que traz em seu bojo uma nova realidade para as políticas públicas. O processo de globalização exigiu níveis mais elevados de qualificação; diante da "crescente circulação de capitais, bens e ideias da nova divisão internacional do trabalho, a educação passa a ser entendida como determinante do desenvolvimento econômico e político das nações" (NETO; CASTRO, 2013, p. 344).

Nesse período, há um processo de reconfiguração da economia para atender às exigências da reestrutura global da economia. A Educação é tida como estratégica para o desenvolvimento econômico do país, e o ensino superior, como um dos propulsores desse desenvolvimento, sendo objeto de discussão e reestruturação, apontado como capaz de inserir o país no cenário econômico mundial.

Com foco na produção de conhecimento que preparasse capital humano para atuar nessa nova realidade e conseguir se correlacionar com outros países, a matéria-prima é a informação e o saber, que requerem investimentos dos governos para sua produção. "Essa realidade multifacetada passou a denominar-se contexto emergente e requer uma nova pedagogia universitária" (DALLA CORTE; SARTURI, 2015, p. 161).

Nessa conjuntura, a educação superior é cerceada pelos processos de globalização, e o Brasil é fortemente influenciado por concepções e orientações de órgãos e instituições internacionais, como a Organização das Nações Unidas para a Educação, a Ciência e a Cultura (UNESCO), a Organização para a Cooperação Econômica e o Desenvolvimento Econômico (OCDE) e o Instituto Internacional para a Educação Superior na América Latina e Caribe (IESALC), voltando-se para um movimento de reestruturação das universidades. 
Essas reformas caracterizaram-se pelo alinhamento às políticas mundiais de educação, buscando aderência às exigências mundiais; "[...] a universidade relevante passa a ser aquela que assume uma perspectiva mais utilitarista, empreendedora, flexível e inovadora e que, além disso, forma para as competências requeridas e alteradas permanentemente pelo mercado de trabalho" (FERREIRA; OLIVEIRA, 2010, p. 52).

A partir desse redimensionamento nas relações sociais e educacionais além das fronteiras nacionais, percebeu-se a necessidade de investir em processos de internacionalização, tendo em vista os desafios de formar profissionais capazes de atuar nessa nova sociedade (MOROSINI; DALLA CORTE, 2018). Nesta perspectiva, as autoras concluem que a internacionalização da educação superior não constitui opção para as universidades "É um movimento que emerge no contexto da sociedade globalizada e pós-globalizada e que requer envolvimento e compreensão acerca dos múltiplos fatores que interferem nas relações políticopedagógicas" (MOROSINI; DALLA CORTE, 2018, p. 116).

Para Ferreira (2017), os sentidos da internacionalização da educação superior estão voltados para a transnacionalização e têm a educação como mercadoria orientada por organismos multilaterais. A educação superior é tida como meio de produção de conhecimentos de interesse do contexto internacional, mostrando-se lucrativa, inclusive, pela via da educação a distância, dentro e fora do território brasileiro.

A despeito do conceito que se adote para globalização e para internacionalização e do quanto os termos apareçam imbricados na literatura, o movimento de globalização tem alterado os processos e as ações de internacionalização nas instituições de educação superior brasileira. A educação superior tornou-se um bem mundial de interesse global. Uma modalidade de educação sem fronteiras que converge para uma ênfase na formação de cidadãos que respeitem e convivam com as diferenças políticas, étnicas e religiosas.

Mas, na globalização de viés neoliberal (SANTOS, 2010), a educação superior passa a ter como função o fortalecimento da economia global, com interesses públicos e privados. Os Estados nacionais deixaram de ter exclusividade na responsabilidade com as políticas, o controle e a avaliação da educação superior.

As universidades que projetam uma inserção internacional, quer seja por motivações de capital simbólico, quer seja por busca de fomento, pautam-se 
pelas avaliações de órgãos internos, mas também objetivam figurar nos rankings internacionais, visto que isso credita um selo de qualidade às instituições.

\section{A INTERNACIONALIZAÇÃO COMO CONCEITO DE QUALIDADE NA ÁREA DA EDUCAÇÃO: INDUÇÃO DO SISTEMA DE AVALIAÇÃO}

A política de avaliação da pós-graduação tem se intensificado, sendo um instrumento de gestão educacional utilizado como forma de regulação e de indução adotada pelo Estado na condução da ação política (FRANÇA, 2014). Criam-se estratégias para o controle de qualidade, no intuito de induzir melhorias constantes na pós-graduação e dentro do próprio sistema de avaliação.

Essa centralidade que a avaliação tem assumido na composição do Sistema Nacional da Pós-Graduação no Brasil tem se realizado na perspectiva de que esta possa impulsionar a qualidade do ensino e da pesquisa produzidos no âmbito da pós-graduação, fazendo do sistema de avaliação um mecanismo indutor de excelência, no qual o Estado impõe critérios que geram competitividade (SOUZA; OLIVEIRA, 2003), configurando a avaliação como condicionante para atingir as metas planificadas.

Esse potencial da avaliação da pós-graduação brasileira é reconhecido pela comunidade científica internacional. Desde os anos 1970 são praticadas avaliações periódicas do Sistema Nacional de Pós-Graduação, por meio da Capes, com revisões sistemáticas do processo e dos instrumentos, constituindo-se, assim, como o país que deu maior contribuição ao desenvolvimento da avaliação da pós-graduação na América Latina, devido à experiência acumulada (LEITE, 2005).

A avaliação é utilizada como um instrumento para medir, mensurar e qualificar, surgindo da necessidade de aferir valor. Para Dias Sobrinho (2003), na perspectiva do Estado avaliador ${ }^{3}$, a avaliação da educação superior tem sido praticada como instrumento de regulação: "Ela sempre se produz num espaço social de valores e disputas de poder, que, aliás, constituem o centro das discussões públicas que a seu respeito se instauram" (DIAS SOBRINHO, 2003, p. 32). O uso

\footnotetext{
3 Segundo Afonso (2000, p. 49), "Esta expressão quer significar, em sentido amplo, que o Estado vem adaptando um ethos competitivo, neodarwinista, passando a admitir a lógica do mercado, através da importação para o domínio público de modelos de gestão privada, com ênfase em resultados e produtos dos sistemas educativos".
} 
da avaliação como instrumento de gestão educacional institui-se num mecanismo utilizado pelos governos para transformar as instituições educativas, ocupando lugar central nas novas configurações do sistema.

As práticas avaliativas que mensuram a qualidade da pós-graduação têm um nível de exigência maior a cada período. À medida que os programas vão alcançando os padrões de qualidade propostos, novos vão sendo estabelecidos numa perspectiva de elevação periódica dos referenciais adotados. Há um controle do processo e dos resultados da avaliação por parte do órgão gestor, pois este se ancora em princípios de uma avaliação classificatória e comparativa (BRASIL, 2017a; 2013b; 2010); ancorado em bases relativas, estabelece diferentes níveis de qualidade de desempenho dos programas em cada área e entre as diferentes áreas dentro das grandes áreas, pautando-se pelos mesmos quesitos e itens avaliativos.

Para Real (2007), qualidade e avaliação são conceitos historicamente construídos; "para se apreender a lógica que pressupõe a avaliação como instrumento de gestão da qualidade do ensino superior, requer-se uma compreensão dos fatores, das tensões e das implicações que estabeleceram as condições para sua configuração atual"' (REAL, 2007, p. 29).

No decorrer do percurso histórico, o Sistema de Avaliação passou por várias mudanças e foram sendo incrementados critérios avaliativos cada vez mais voltados para os índices e resultados de impactos. Foram estabelecidos parâmetros para auxiliar na avaliação da qualidade dos programas de pós-graduação, como o Programa Qualis, utilizado pela primeira vez na Trienal 2001, o qual, embora não seja consenso na comunidade acadêmica, tem se consolidado como instrumento para qualificação da produção científica e consequente balizador para avaliação dos programas de pós-graduação.

No entanto, para que os programas sejam alçados ao nível de excelência, referenciado nas notas 6 e 7 , há outros indicadores que são apensados aos critérios de avaliação. Entre esses, destaca-se a internacionalização, que tem se apresentado como um fator de legitimação da circulação do conhecimento e formação de recursos humanos. Morosini e Dalla Corte (2018), Morosini e Nascimento (2017), Miranda e Stallivieri (2017), Morosini et al. (2016) apontam que a internacionalização tem se constituído como indicador de qualidade na pós-graduação.

Para Morosini e Nascimento (2017, p. 2), a internacionalização da educação superior tem se constituído como uma das principais metas da universidade 
contemporânea e "está relacionada à qualidade, à excelência, à inovação, ao conhecimento", firmando-se como critério basilar, entre outros elementos, para a avaliação de qualidade de um programa de pós-graduação de excelência.

Souza (2017) afirma que a internacionalização tem ocupado espaço central nos debates sobre a qualidade da educação superior, passando a configurar-se como uma forma de induzir a qualidade, havendo a necessidade de ser estimulada por meio de políticas institucionais, visto que a internacionalização demanda sintonia entre formulação e avaliação de metas.

Contudo, mesmo que a internacionalização venha se constituindo como um indicador de qualidade, não há clareza e objetividade nos critérios adotados na avaliação dessa internacionalização, havendo a necessidade de "fundamentos e definições para a construção de políticas públicas para internacionalização do ensino superior" (MIRANDA; STALLIVIERI, 2017, p. 592).

Sousa (2017) adverte que, como indicador de qualidade, a internacionalização ainda constitui um elemento que precisa ser implementado e avaliado nas práticas acadêmicas, a fim de serem verificadas as estratégias adotadas pela universidade para promover essa internacionalização, visto que a ausência da clareza conceitual do que seja internacionalização da educação superior para os órgãos gestores permite que as instituições de nível superior (IES) imprimam múltiplas interpretações a esse processo.

Miranda e Stallivieri (2017) também apontam para a necessidade de serem criadas políticas para a internacionalização das instituições de ensino superior brasileiras, visto que não há documentos do governo brasileiro que explorem de forma clara a internacionalização e que tratem-na como uma política pública. Assim, o tema ainda precisa de amadurecimento e sistematização de ações, com vistas à elaboração conjunta de políticas públicas de Estado que direcionem para uma internacionalização do sistema de ensino superior.

Mesmo que não haja um documento nacional orientador da política de internacionalização, esta é expressa nos documentos direcionados para a avaliação da pós-graduação, descrita nos documentos de área e nos relatórios de avaliação. Assim, no intuito de verificar como a internacionalização tem se constituído um indicador de qualidade na pós-graduação em Educação, analisaram-se as orientações constantes nos documentos de área das avaliações trienais 2009, 2013a, 2016 e 2019, bem como os relatórios 2010, 2013 e 2017. 
Os documentos da área trazem orientações específicas sobre os processos de Inserção Internacional. No documento de área da avaliação trienal 2010, havia a informação sobre as atribuições das notas 6 e 7, pontuação máxima aferida aos programas; uma das condições era de que os programas "apresentem desempenho equivalente aos dos centros internacionais de excelência na área" e um dos três critérios apresentados trata do nível de qualificação, de produção e de desempenho equivalentes aos dos centros internacionais de excelência na formação de recursos humanos: considera-se o índice de publicações em periódicos A1 e A2 e livros L4, além de indicadores de inserção internacional e nacional dos programas (BRASIL, 2009).

A produção científica era apontada como o principal indicador de excelência nos programas de pós-graduação. Assim, para decidir se um curso seria classificado nas notas 6 ou 7, foi utilizado o cálculo das médias ponderadas da produção dos programas com conceito 5 . Os programas que atendiam aos requisitos de produção internacionalizada foram analisados em quatro outros aspectos, dos quais três estavam relacionados à internacionalização: "[...] pesquisas realizadas em parceria com centros de excelência internacionais, atividades de docência e universidades estrangeiras e intercâmbio de alunos estrangeiros [...]" (BRASIL, 2010, p. 16).

Nessa trienal, a comissão de área indicou cinco programas para o conceito 6, sendo eles da UNISINOS, UFSCAR (Educação Especial), USP, UFF e PUC-RS; e três programas para o conceito 7, da UERJ, PUC-Rio e UFMG.

Na trienal de 2013, o documento de área apresenta um texto mais elaborado no item Inserção Internacional, elencando quatro eixos por meio dos quais a internacionalização vinha sendo desenvolvida na área de Educação: a) internacionalização realizada por meio de publicações em livros e periódicos internacionais; b) desenvolvimento de pesquisa e atividades em redes com envolvimento institucional; c) atuação de pesquisadores e professores brasileiros em programas estrangeiros e de pesquisadores estrangeiros nos programas do Brasil; d) cooperação internacional envolvendo trânsito de alunos (BRASIL, 2013a).

Para que fosse garantida a excelência nos níveis 6 e 7, permaneceu como indicador a produção científica veiculada em periódicos A e livros L4; a participação em redes institucionais de pesquisa; intercâmbio de docentes e discentes; e potencial de formação de pesquisadores com perfil compatível aos centros de excelência no exterior. 
A comissão de área, após analisar os dados de produção e internacionalização, classificou três programas no conceito 7, sendo eles da UNISINOS, UERJ e UFMG; e seis programas para o conceito 6, da USP, PUCRS, UFSCAR (Educação Especial), PUC-Rio, PUC-SP e UFRGS (BRASIL, 2013b).

Na quadrienal de 2016, o documento de área apresenta os mesmos eixos constantes em 2013, mas, ao relacionar os indicadores para concessão de notas 6 e 7, o quesito internacionalização apresenta-se de forma ampliada e objetiva. Para avaliar o grau de internacionalização, foram adotados os seguintes critérios:

Pós-doutoramento e participação como professor visitante do corpo docente do programa em centros de excelência no exterior; Professores visitantes recebidos pelo programa; Intercâmbio de alunos com IES do exterior (sobretudo bolsas-sanduíche); Participação de docentes e doutorandos em eventos internacionais de alto nível; Financiamento internacional de projetos e outras atividades; Participação de docentes em comitês, consultorias, editoria de periódicos e outras atividades no exterior; Participação em projetos de pesquisa de colaboração internacional. (BRASIL, 2016, p. 21).

Ao apresentarem o relatório da avaliação quadrienal, a comissão de área detalhou os indicadores de internacionalização que foram considerados na conferência de evidências de realizações de ações da internacionalização, como: eventos e cursos internacionais; intercâmbios; editoração; redes internacionais; financiamento e premiações; e inserção acadêmica e impacto local da internacionalização.

Nessa quadrienal, a comissão de área indicou quatro programas para o conceito 6 e quatro programas para o conceito 7. O Conselho Técnico Científico (CTC) manteve apenas dois programas no estrato 7 e seis programas no estrato 6 (BRASIL, 2017a). Mas, após recursos impetrados e avaliados, três programas voltaram a figurar nos programas nota 7 e seis programas foram classificados no conceito 6.

O documento de área publicado em 2019 destaca a importância de aumentar a interlocução da área com a comunidade acadêmica internacional, numa correlação que apresente foco nos objetivos do PPG, devendo apresentar pertinência na sua realização, não se configurando apenas como um objetivo vazio, tendo claro que alguns programas têm melhores condições de trabalhar aspectos de sua internacionalização do que outros. 
Aponta-se que, nos últimos anos, a área tem aumentado ações indicativas de internacionalização, apresentando interações e pesquisas em rede de pesquisas no exterior, ampliação do número de professores visitantes estrangeiros, orientações em cotutela e projetos com financiamento internacional (BRASIL, 2019a); mas, em comparação às outras áreas, esses avanços ainda são pouco expressivos.

Ressalta-se a importância de se aprimorar e impulsionar a internacionalização da área no quadriênio em curso, devendo ser prioridade de todos os programas, e não apenas dos grupos de excelência.

Essas orientações estão em consonância com o já estabelecido nos relatórios das comissões do Plano Nacional de Pós-Graduação e na nova ficha avaliativa apresentada pelo Grupo de Trabalho (GT) da Ficha de Avaliação, que foi instituído pela Portaria n. 148 de 14 de julho de 2018, com o objetivo de rever e simplificar as fichas utilizadas no âmbito da CAPES (BRASIL, 2019b).

O relatório do PNPG (BRASIL, 2017b) orientava induzir as IES a desenvolverem um Plano de Internacionalização, vinculando os recursos e o apoio para internacionalização à existência desse Plano Institucional. Assim, também, o documento de área orienta que os programas conceituem e planejem sua política de internacionalização de acordo com sua missão e objetivos, devendo haver uma correlação institucional indicando inserção no planejamento estratégico de programa.

A internacionalização será um elemento analisado em todos os programas, e não apenas aos candidatos às notas 6 e 7. Na nova ficha de avaliação aprovada na 182a Reunião do CTC-ES, o item "internacionalização" passou a compor a ficha como parte do quesito "impacto na sociedade".

A internacionalização tem se incorporado nas práticas avaliativas da pósgraduação como um elemento distintivo da qualidade e agora, de forma mais clara e objetiva, passou a compor diretamente o instrumento de avaliação dos programas, ou seja, não serão apenas os programas que buscam figurar no grupo considerado de excelência que terão como foco as ações de internacionalização, todos deverão propor e buscar figurar nesse novo cenário, pois isso incidirá na avaliação dos programas.

\section{CONSIDERAÇÕES FINAIS}

Há evidências de que a política nacional de educação superior está alinhada a uma agenda globalmente estruturada para educação (DALE, 2004), fazendo 
com que o processo de internacionalização deixe de ser uma opção e passe a ser obrigatoriedade para as universidades.

Os critérios utilizados na avaliação apontam que, quanto maior forem as evidências de realizações de ações de internacionalização nos programas, melhor será a classificação deles, evidenciando, assim, que, para além da produção intelectual, o que tem balizado a avaliação da qualidade na pós-graduação são as ações de internacionalização.

Essa tendência tem se confirmado nas orientações contidas no documento de área apresentado em 2019 e na composição da ficha de avaliação da próxima quadrienal, que traz a internacionalização como parte dos itens a serem avaliados, não sendo mais apenas elemento para distinguir os programas 6 e 7 .

Uma questão que ainda precisa ser clarificada é como internacionalização e visibilidade do programa serão analisadas dentro do quesito impacto na sociedade, o que a área vai considerar que é ser internacional e ter visibilidade, visto que a visibilidade tem sido mensurada pelos grandes rankings internacionais apontados por alguns estudos (THIENGO, 2018; THIENGO; BIANCHETTI; ALMEIDA, 2019) como insuficiente para medir a qualidade da ciência brasileira, fortalecendo a concepção de universidade e ciência alinhadas ao interesse do mercado, constituindo-se em ferramentas meritocráticas.

\section{REFERÊNCIAS}

AFONSO, A. J. Avaliação Educacional: regulação e emancipação. São Paulo: Cortez, 2000.

BRASIL. Ministério da Educação. Coordenação de Aperfeiçoamento de Pessoal de Nível Superior. Documento da Área de Educação 2019. Brasília, DF: CAPES, 2019a. Disponível em: http://capes.gov.br/images/educacao_doc_area_2.pdf Acesso em: 10 maio 2019.

BRASIL. Ministério da Educação. Coordenação de Aperfeiçoamento de Pessoal de Nível Superior. Ficha de avaliação. Brasília, DF: CAPES, 2019b. Disponível em: http://capes.gov. br/images/educacao_doc_area_2.pdf. Acesso em: 10 maio 2019.

BRASIL. Ministério da Educação. Coordenação de Aperfeiçoamento de Pessoal de Nível Superior. Relatório da Avaliação Quadrienal 2016. Brasília, DF: CAPES, 2017a. Disponível em: http://capes.gov.br/avaliacao/sobre-as-areas-de-avaliacao/100-dav/9532-educacaomemoria-da-area. Acesso em: 5 mar. 2019. 
BRASIL. Ministério da Educação. Coordenação de Aperfeiçoamento de Pessoal de Nível Superior. Comissão especial de acompanhamento do PNPG 2011-2020. Relatório final 2016: sumário executivo. Brasília, DF: CAPES, 2017b. Disponível em: https://www.capes. gov.br/plano-nacional-de-pos-graduacao. Acesso em: 5 mar. 2019.

BRASIL. Ministério da Educação. Coordenação de Aperfeiçoamento de Pessoal de Nível Superior. Documento da Área de Educação 2016. Brasília, DF: CAPES, 2016. Disponível em: http://capes.gov.br/avaliacao/sobre-as-areas-de-avaliacao/100-dav/9532-educacaomemoria-da-area. Acesso em: 10 maio 2018.

BRASIL. Ministério da Educação. Coordenação de Aperfeiçoamento de Pessoal de Nível Superior. Documento da Área de Educação 2013. Brasília, DF: CAPES, 2013a. Disponível em: http://capes.gov.br/avaliacao/sobre-as-areas-de-avaliacao/100-dav/9532-educacaomemoria-da-area. Acesso em: 10 maio 2018.

BRASIL. Ministério da Educação. Coordenação de Aperfeiçoamento de Pessoal de Nível Superior. Relatório da Avaliação Trienal 2013. Brasília, DF: CAPES, 2013b. Disponível em: http://capes.gov.br/avaliacao/sobre-as-areas-de-avaliacao/100-dav/9532-educacaomemoria-da-area. Acesso em: 5 mar. 2017.

BRASIL. Ministério da Educação. Coordenação de Aperfeiçoamento de Pessoal de Nível Superior. Relatório da Avaliação Trienal 2010. Brasília, DF: CAPES, 2010. Disponível em: http://capes.gov.br/avaliacao/sobre-as-areas-de-avaliacao/100-dav/9532-educacaomemoria-da-area. Acesso em: 5 mar. 2017.

BRASIL. Ministério da Educação. Coordenação de Aperfeiçoamento de Pessoal de Nível Superior. Documento da Área de Educação 2009. Brasília, DF: CAPES, 2009. Disponível em: http://capes.gov.br/avaliacao/sobre-as-areas-de-avaliacao/100-dav/9532-educacaomemoria-da-area. Acesso em: 10 maio 2018.

CELLARD, A. A análise documental. In: POUPART, J.; DESLAURIERS, J. P.; GROULX, L. (Org.). A pesquisa qualitativa: enfoques epistemológicos e metodológicos. Petrópolis: Vozes, 2008. p. 295-334.

DALE, R. Globalização e educação: demonstrando a existência de uma "cultura educacional mundial comum" ou localizando uma "agenda globalmente estruturada para a educação"? Educação e Sociedade, Campinas, v. 25, n. 87, p. 423-60, 2004. Disponível em: http:// www.scielo.br/pdf/es/v25n87/21464.pdf. Acesso em: 10 maio 2019.

DALLA CORTE, M. G.; SARTURI, R. C. Políticas públicas para a formação de professores e contextos emergentes na educação superior. Revista Internacional de Educação Superior, Campinas, v. 1, n. 2, p.160-81, out./dez. 2015. Disponível em: https://www.fe.unicamp. br/revistas/ged/RIESup. Acesso em: 09 out. 2019. 
DE WIT, H.; HUNTER, F.; HOWARD, L.; EGRON-POLAK, E. (Org.). Internationalisation of Higher Education, Milão, 2015. Disponível em: http://www.europarl.europa.eu/ RegData/etudes/STUD/2015/540370/IPOL_STU(2015)540370_EN.pdf. Acesso em: 20 maio 2019.

DIAS SOBRINHO, J. Avaliação da educação superior: regulação e emancipação. Avaliação. Revista da Rede de Avaliação Institucional da Educação Superior, Campinas, ano 8, v. 8, n. 2, p. 31-47, 2003. Disponível em: http://periodicos.uniso.br/ojs/index.php/avaliacao/ article/view/1221. Acesso em: 30 out. 2018.

EUROPEAN ASSOCIATION FOR INTERNATIONAL EDUCATION. What's in a name? Refocusing internationalisation of higher education. EAIE, 2015. Disponível em: https://www.eaie. org/blog/whats-in-a-name-refocusing-internationalisation-of-higher-education.html. Acesso em: 10 maio 2019.

FERREIRA, J. S. Revelações do Sinaes: (des)caminhos da avaliação da qualidade nos cursos de Pedagogia no Brasil. 2017. 310 p. Tese (Doutorado em Educação) - Universidade Federal do Rio Grande do Sul, Porto Alegre, RS, 2017.

FERREIRA, S; OLIVEIRA, J. F. As reformas da educação superior no Brasil e na união europeia e os novos papéis das universidades públicas. Nuances: estudos sobre Educação, Presidente Prudente, v. 17, n. 18, p. 50-67, jan./dez. 2010. Disponível em: http://revista. fct.unesp.br/index.php/Nuances/article/view/724. Acesso em: 09 de out. 2019.

FRANÇA, I. A. Avaliação da Capes e gestão de programas de excelência na área de Educação. 2014. 249 p. Tese (Doutorado em Educação)- Pontifícia Universidade Católica do Rio de Janeiro, Rio de Janeiro, RJ, 2014.

GRAMSCI, A. Cadernos do cárcere: os intelectuais; o princípio educativo; jornalismo. 8. ed. Tradução de Carlos Nelson Coutinho. Rio de Janeiro: Civilização Brasileira, 2016. v. 2.

KNIGHT J. The changing landscapes of higher education internationalisation - for better or worse? Perspectives: Policy and Practice in Higher Education, London, v. 17, p. 84-90, 2013. Disponível em: https://www.tandfonline.com/doi/full/10.1080/13603108.2012.7 53957?scroll=top\&needAccess=true. Acesso em: 9 out. 2019.

KNIGHT, J. Cinco verdades a respeito da internacionalização. International Higher Education, Campinas, n. 69, out. 2012. Edição brasileira (Revista Ensino Superior Unicamp) publicada mediante acordo de cooperação entre Unicamp e Boston College. Disponível em: https://www.revistaensinosuperior.gr.unicamp.br/international-higher-education/ cinco-verdades-a-respeito-da-internacionalizacao. Acesso em: 12 jun. 2019. 
KNIGHT, J. Comercialización de servicios de educación superior: implicaciones del AGCS. In: GARCÍA-GUADILLA, C. (Org.). El difícil equilibrio: la educación superior como bien público y comercio de servicios Implicaciones del AGCS (GATS). Lima: Universidad de Lima-Columbus, 2004. p. 37-63. Disponível em: https://www.columbus-web.org/es/ nuestros-activos/publicaciones/item/64-el-dif\%C3\%ADcil-equilibrio-la-educaci\%C3\%B3nsuperior-como-bien-p\%C3\%BAblico-y-comercio-de-servicios.html. Acesso em: 10 maio 2019.

KNIGHT, J. Updating the Definition of Internationalization. International Higher Education, v. 33, p. 2-3, 2003. Disponível em: https://scholar.google.com.br/scholar?q=Knight,J. (2003). Update+Internationalization+Definition. International+Higher+Education,33,23.\&hl=pt-BR\&as_sdt=0\&as_vis=1\&oi=scholart. Acesso: 14 maio 2019.

KNIGHT, J. Internationalization: elements and checkpoints (Research Monograph, n. 7). Canadian Bureau for International Education (CBIE), Canadá, v. 7, p. 1-15, 1994. Disponível em: https://files.eric.ed.gov/fulltext/ED549823.pdf. Acesso em: 10 out.

LEITE, D. Reformas universitárias: Avaliação Institucional Participativa. Petrópolis: Vozes, 2005. 141 p. Disponível em: http://www.ufrgs.br/inov/docs/refrmasuniv_avaliainstpartic. Acesso em: 12 jun. 2019.

MIRANDA, J. A. A.; STALLIVIERI, L. Para uma política pública de internacionalização para o ensino superior no Brasil. Avaliação: Revista da Avaliação da Educação Superior, Sorocaba, v. 22, n. 3, p. 589-613, 2017. Disponível em: http://periodicos.uniso.br/ojs/index.php/ avaliacao/article/view/3135. Acesso em: 18 out. 2018.

MOROSINI, M. C. Estado do conhecimento sobre internacionalização da educação superior Conceitos e práticas. Educar em Revista, Curitiba, v. 22, n. 28, p. 107-24, 2006. Disponível em: https://revistas.ufpr.br/educar/article/view/7614. Acesso em: 30 out. 2018.

MOROSINI, M. C.; DALLA CORTE, M. G. Teses e realidades no contexto da internacionalização da educação superior no Brasil. Revista Educação em Questão, Natal, v. 56, n. 47, p. 97120, 12 abr. 2018. Disponível em: https://periodicos.ufrn.br/educacaoemquestao/article/ view/14000. Acesso em: 18 out. 2018.

MOROSINI, M. C.; FERNANDES, C. M. B.; LEITE, D.; FRANCO, M. E. D. P.; CUNHA, M. I; ISAIA, S. M. A. A qualidade da educação superior e o complexo exercício de propor indicadores. Revista Brasileira de Educação, Rio de Janeiro, v. 21, n. 64, p. 13-37, jan./mar. 2016. Disponível em: http://www.anped.org.br/news/rbe-revista-brasileira-de-educacao-v-21n-64-jan-mar-2016. Acesso em: 18 out. 2018. 
MOROSINI, M. C.; NASCIMENTOL, L. M. Internacionalização da educação superior no Brasil: a produção recente em teses e dissertações. Educação em Revista, Belo Horizonte, n. 33, 2017. Disponível em: http://educacaoemrevistaufmg.com.br/edio-anterior/educacaoem-revista-vol-33-ano-2017. Acesso em: 18 out. 2018.

NETO, A. C.; CASTRO, A. M. D. A. A expansão da pós-graduação em cenários de globalização: recortes da situação brasileira. Inter-Ação, Goiânia, v. 38, n. 2, p. 339-62, maio/ago. 2013. Disponível em: https://www.revistas.ufg.br/interacao/article/view/26108. Acesso em: 9 out. 2019.

REAL, G. C. M. A qualidade revelada na educação superior: impactos da política de avaliação no Brasil. 2007. 206 p. Tese (Doutorado em Educação) - Universidade de São Paulo, São Paulo, 2007.

ROBL, F. Quo vadis Educação Superior na Colômbia? Expansão, acreditação e internacionalização. 2015. 240 p. Tese (Doutorado em Educação) - Universidade de São Paulo, São Paulo, 2015.

SANTOS, B. S. A universidade no século XXI: para uma reforma democrática e emancipatória da universidade. 3a. ed. São Paulo: Cortez, 2010.

SOUSA, J. V. Internacionalização da Educação Superior como indicador do Sinaes: de qual qualidade estamos falando? Educação, Porto Alegre, v. 40, n. 3, p. 343-56, set./dez., 2017. Porto Alegre. Disponível em: http://revistaseletronicas.pucrs.br/ojs/index.php/faced/ article/view/28979. Acesso em: 9 out. 2019.

SOUZA, S. Z. L; OLIVEIRA, R. P. Políticas de avaliação da educação e quase mercado no Brasil. Educação \& Sociedade. Campinas, v. 24, n. 84, p. 873-95, set. 2003. Disponível em: http://www.scielo.br/scielo.php?script=sci_arttext\&pid=S0101-73302003000300007\&ln g=en\&nrm=iso>. Acesso em: 9 out. 2019.

THIENGO, L. C. Universidade de classe mundial e o consenso pela excelência: tendências globais e locais. 2018. 449 p. Tese (Doutorado em Educação) - Universidade Federal de Santa Catarina, Florianópolis, SC, 2018.

THIENGO, L. C; BIANCHETTI, L; ALMEIDA, M. L. P. Rankings: estratégia de defesa da universidade pública? Revista da FAEEBA - Educação e Contemporaneidade, Salvador, v. 28, n. 55, p. 28-42, maio/ago. 2019. Disponível em: http://www.revistas.uneb.br/index. php/faeeba/article/view/7167. Acesso em: 9 out. 2019. 


\section{Sobre as autoras:}

Eliane Souza de Carvalho: Doutoranda em Educação na Universidade Federal da Grande Dourados (UFGD). Técnica de Nível Superior/Editora na Universidade Estadual de Mato Grosso do Sul (UEMS).E-mail: elianesouzadecarvalho@gmail.com, Orcid: https://orcid.org/0000-0002-3253-474X

Giselle Cristina Martins Real: Pós-doutora e doutora em Educação pela Universidade de São Paulo (USP). Professora e pesquisadora da Faculdade de Educação da Universidade Federal da Grande Dourados (UFGD), atuando na graduação e pós-graduação stricto sensu. Coordenadora do Programa de Pós-Graduação em Educação da UFGD. E-mail: gisellereal@ufgd.edu.br, Orcid: http://orcid.org/0000-0002-8855-4141

Recebido em 22 de outubro de 2019. Aprovado em 15 de maio de 2020. 
